\title{
CHRONIC MILD STRESS: UM ESTUDO SOBRE A INTERAÇÃO ENTRE SUBMISSÃO AO PROTOCOLO DE ESTRESSORES, COMPORTAMENTO OPERANTE E PRIVAÇÃO
} CHRONIC MILD STRESS: AN EXPERIMENT ABOUTTHE INTERACTION AMONG
SUBMISSIONTO STRESS PROTOCOL, OPERANT BEHAVIOR AND DEPRIVATION

\author{
Clarissa Moreira Pereira ${ }^{1}$ e Tereza Maria de Azevedo Pires Sério (in memoriam) \\ PONTIFÍCIA UNIVERSIDADE CATÓLICA DE SÃO PAULO
}

\begin{abstract}
RESUMO
O chronic mild stress (CMS) é um modelo experimental para estudo dos efeitos da exposição a esses estressores no comportamento dos sujeitos. No presente estudo, pretendeu-se verificar se o protocolo completo, e não apenas alguns estressores apresentados isoladamente (privação de água e privação de alimento), seria responsável pelos efeitos comumente descritos na literatura (diminuição na ingestão e preferência por substância doce pela submissão ao protocolo). Foi verificada, também, a interferência de sessões operantes em esquema concorrente (água-sacarose) nos efeitos considerados. Os resultados encontrados foram analisados com relação à ingestão de líquidos nos testes da gaiola viveiro. Tanto a privação, isoladamente, quanto o protocolo incompleto (sem privação) produziram efeitos na ingestão e preferência de líquidos. Além disso, foi encontrada diferença nos valores de ingestão entre os sujeitos que passaram por sessões operantes e os sujeitos que não passaram (valores maiores para os primeiros). Com relação aos resultados, duas sugestões são colocadas: (a) a manipulação neonatal pode ser uma variável responsável pela não produção de todos os efeitos do protocolo no comportamento dos sujeitos; e (b) a exposição prolongada à sacarose pode ter efeitos similares à analgesia nos sujeitos, fazendo com que os possíveis efeitos do protocolo de estressores não sejam produzidos.
\end{abstract}

Palavras-chave: protocolo de estressores, privação, comportamento operante, manipulação neonatal, exposição à sacarose.

\section{ABSTRACT}

Chronic mild stress (CMS) is an experimental model that attempts to study the effects of the exposition to these stressors in the subjects' behavior. In the present experiment, the purpose was to identify if whole protocol, and not some of the stressor stimuli specifically (water and food deprivation) is responsible for producing the effects frequently described in literature (decreased sweet substance ingestion and preference when submitted to the protocol). It was also verified the influence of operant concurrent schedule sessions (water-sucrose) in the effects considered. The results were described on sucrose ingestion and preference. Deprivation itself and incomplete protocol (with no deprivation conditions) produced effects on sucrose preference and ingestion. Besides, there was difference in sucrose ingestion between subjects submitted to the operant condition and subjects that did not go this condition (the ingestion showed to be greater for the first ones). According to these results, there are two possible suggestions: (a) neonatal handling can be responsible for the inexistency of the common effects of the protocol in the subjects' behavior; and (b) the continuous exposure to sucrose can have similar effects to analgesia, making it possible that effects of the protocol are not produced.

Keywords: stress protocol, deprivation, operant behavior, neonatal handling, exposure to sucrose.

Modelos animais ou experimentais são tentativas de reprodução de fenômenos comportamentais (ou fisiológicos) em determinadas espécies animais, no laboratório, para posterior uso dos resultados obtidos na com- preensão da espécie humana (Keehn, 1979; Willner, 1991). São, nesse sentido, a "representação de uma realidade específica, possível de ser manipulada, que permite a realização de análise para o seu melhor conhecimento,

\footnotetext{
${ }^{1}$ Avenida Irerê, n. 2.060, apto. 203 - CEP: 04064-005 - Planalto Paulista - São Paulo/SP - Tel.: (11) 3459-2349 /(11) 9886-6684. E-mail: clarissapereira@gmail.com

Notas de agradecimento e informação sobre financiamento - A autora Clarissa Moreira Pereira gostaria de agradecer carinhosamente à professora doutora Nilza Micheletto a revisão cuidadosa do artigo e seus comentários.

O estudo foi conduzido com financiamento parcial da Capes, como requisito para a obtenção do título de mestre pelo programa de Psicologia Experimental: Análise do Comportamento, da Pontifícia Universidade Católica de São Paulo - PUC/SP.
} 
inferindo dados e testando hipóteses" (Guimarães \& Mázaro, 2004, p. 12). Esses modelos são utilizados para estudo de diversas psicopatologias, como, por exemplo, a depressão.

Segundo Willner, Towell, Sampson, Sophokleous e Muscat (1987), apenas alguns modelos animais da depressão atendem aos critérios de validade para que possam ser considerados para estudo em laboratório. Esses critérios dizem respeito à possibilidade de uso do modelo em questão como ferramenta de entendimento e estudo de determinada condição humana, sendo descritos na psicopatologia como critérios de validade aparente, validade preditiva e validade de constructo (ou de construção teórica).

Um dos modelos que atendem a esses critérios é o estresse crônico moderado, ou chronic mild stress (CMS). Nesse modelo, ratos são submetidos a um protocolo de estressores apresentados de maneira crônica e alternada, com alguns intervalos entre eles. Todos os estímulos estressores do protocolo são considerados moderados, visto que apenas o conjunto produz as alterações observadas, e não cada estressor isoladamente. As medidas utilizadas para avaliar os efeitos desse protocolo variam de estudo para estudo, mas a medida mais comumente reportada é a de ingestão e preferência por líquido doce (sacarose ou sacarina, dissolvidas em água).

Em seu estudo utilizando o modelo, Willner et al. (1987) submeteram ratos a um protocolo composto dos estressores (a) privação de água e comida; (b) iluminação contínua; (c) inclinação da gaiola a $30^{\circ}$; (d) agrupamento na gaiola (outro sujeito); (e) gaiola suja; (f) temperatura reduzida $\left(10^{\circ} \mathrm{C}\right)$; (g) ruído branco intermitente; (h) luz estroboscópica; (i) exposição a uma garrafa vazia após período de privação de água; (j) acesso restrito à comida; (k) cheiro novo; (l) presença de um objeto estranho na caixa (madeira ou plástico). Quatro diferentes experimentos foram realizados, e a exposição a cada experimento variou em número de estressores (para um dos experimentos, utilizaram-se apenas os estressores " a" a "f"), em intensidade (em outro experimento, a intensidade dos estressores foi aumentada com o decorrer das semanas) e em número de semanas (cinco, seis ou nove semanas, a depender do experimento).

A medida dos efeitos dos estressores sobre os sujeitos foi a de ingestão e preferência por sacarose ou sacarina (substância doce), antes, durante e depois da submissão ao protocolo. Além disso, em um dos experimentos, foi administrado antidepressivo tricíclico (DMI) aos sujeitos a partir da terceira semana de exposição aos estressores, para avaliação de seu efeito.

Para todos os sujeitos experimentais houve, durante o período de exposição ao protocolo, diminuição na ingestão da substância doce (sacarose ou sacarina), mantendo-se a ingestão de água constante em relação à ingestão anterior ao protocolo (portanto, houve diminuição da preferência observada inicialmente por essas substâncias, já que a ingestão de água passou a ser muito parecida com a de sacarose ou sacarina). Esse efeito foi discutido pelos autores como possivelmente um efeito de diminuição de sensibilidade à recompensa, ou anedonia (algo que tinha, inicialmente, valor de recompensa medido pela ingestão e preferência - passou a não mais ter esse valor após a história de submissão ao protocolo - medido pela diminuição na ingestão e preferência após essa história). 
Para os sujeitos que receberam antidepressivo, houve recuperação dos níveis iniciais, tanto de ingestão quanto de preferência, após a segunda semana de administração de DMI.

Diversos estudos foram realizados utilizando-se o CMS. Em vários deles (por exemplo, Barr \& Phillips, 1998; Dalla et al., 2005; Konkle et al., 2003; Vigorito, Kruse, \& Carretta, 1994), alterações na ingestão e preferência por substância doce pela submissão ao protocolo de estressores também foram encontradas.

Porém, alguns autores reportaram a ausência de tais efeitos quando apenas um dos estressores do protocolo, a privação, foi excluído do conjunto na aplicação aos sujeitos (Forbes, Stewart, Matthews, \& Reid, 1996; Matthews, Forbes, \& Reid, 1995). Nesses estudos, grupos de sujeitos submetidos aos demais estressores do protocolo, com exceção das privações de água e alimento, não apresentaram os efeitos de diminuição na ingestão e preferência por sacarose. A discussão feita por Matthews et al. e Forbes et al. apontou para o papel crucial da privação na produção do que Willner et al. (1987) chamaram de anedonia. Para os primeiros, a privação seria responsável pela diminuição no peso dos sujeitos, o que faria com que ingerissem menor quantidade da substância doce (segundo eles, a ingestão é proporcional ao "tamanho" dos sujeitos), não tendo esse efeito relação com diminuição em sensibilidade à recompensa (anedonia). Dessa forma, com ausência de privação (e, portanto, ausência em diminuição do peso), esse efeito não seria observado.

Ainda, outros estudos (Cardoso, 2008; Dolabela, 2004; Rodrigues, 2005; Thomaz,
2001, 2005) demonstraram esse mesmo efeito a partir da interação entre o protocolo de estressores e a produção de consequência por uma resposta operante (a saber, resposta de pressão à barra produzindo água ou água com sacarose em esquema concorrente idêntico para as duas barras).

Nesses estudos, ratos foram submetidos a sessões operantes antes e depois (Thomaz, 2001, 2005), ou antes, durante e depois do protocolo (Cardoso, 2008; Dolabela, 2004; Rodrigues, 2005), tendo sido demonstrado que, para os sujeitos submetidos ao protocolo e que nunca passaram por nenhuma sessão operante, houve diminuição na ingestão e preferência por sacarose, não havendo retorno da ingestão aos níveis anteriores ao início do protocolo, quando este foi suspenso. Com relação aos sujeitos que passaram por sessões operantes, foram também observadas diminuições em ingestão e preferência durante a exposição ao protocolo. No entanto, após sua suspensão, houve volta dos valores aos níveis inicialmente observados, ou seja, aos níveis de ingestão e preferência de líquidos apresentados antes da exposição ao protocolo de estressores, assim como ocorreu no estudo de Willner et al. (1987) para os sujeitos que tiveram aplicação do antidepressivo tricíclico (DMI).

Levando-se em conta tais considerações a respeito de estudos com o modelo CMS, a presente pesquisa pretendeu investigar se diferenças na ingestão e preferência de líquidos (sacarose dissolvida em água e água pura) podem ser decorrentes especificamente de privação de água e alimento ou do protocolo como um todo (com privação em conjunto com os demais estressores). Ainda, se seria possível identificar diferenças nessas medidas 
(ingestão e preferência) por conta de os sujeitos passarem também por sessões operantes (sessões de produção de consequência).

Para tanto, as condições de privação foram isoladas do protocolo, e os seguintes grupos foram propostos: (a) protocolo completo, com e sem condição operante; (b) protocolo incompleto - sem privação de água e de alimento -, com e sem condição operante; e (c) apenas privação de água e alimento, com e sem condição operante.

\section{MÉTODO}

\section{Sujeitos}

Foram utilizados no estudo 18 ratos machos, experimentalmente ingênuos, da linhagem Wistar, alojados individualmente a partir do desmame.

\section{Equipamento}

Foram utilizadas caixas operantes da marca Med Associates, conectadas a uma interface, para registro das sessões. As caixas operantes eram equipadas com uma ou duas barras, sendo as duas barras, quando utilizadas, localizadas em paredes opostas da caixa (uma de frente para a outra). Os estressores utilizados foram uma luz estroboscópica com regulador de velocidade de flashes, um aparelho de áudio e um regulador de decibéis, serragem, 10 latas redondas com aproximadamente $7 \mathrm{~cm}$ de diâmetro e $1,5 \mathrm{~cm}$ de altura, desodorante purificador de ar, timer para controle do ciclo luminoso. Caixas viveiro de material plástico, para alojamento dos sujeitos para cruzamento (geração dos sujeitos do experimento) e período até o desmame dos sujeitos experimentais, foram utilizadas. Após desmame, foram utilizados dois tipos de gaiolas, ambas de material metálico. Um tipo era especialmente preparado para a implementação do protocolo de estressores (a prateleira de gaiolas é própria para inclinação da caixa, um dos estressores).

\section{Procedimentos \\ (CONDIÇÕES EXPERIMENTAIS)}

\section{Condição preparatória (nascimento ao desmame)}

A condição preparatória descreve os procedimentos ocorridos (alguns dos cuidados tomados) desde a concepção dos sujeitos, seu nascimento, até o desmame.

\section{Alojamento}

Desde o cruzamento para geração dos sujeitos deste experimento, ratos (três fêmeas e um macho por caixa) foram alojados em uma sala isolada, com temperatura e ruído controlados, e mantidos nessa sala até que os sujeitos nascessem e atingissem a idade para desmame (aproximadamente 30 dias).

A partir de então, os sujeitos foram separados e alojados individualmente em duas salas separadas, ambas isoladas. As salas foram divididas para que os estressores, quando implementados a alguns dos sujeitos, não interferissem nos demais, que não teriam a aplicação do protocolo.

A temperatura e a luminosidade de ambas as salas foram controladas por exaustor e timer, respectivamente. $\mathrm{O}$ ciclo luminoso foi de 12 horas de claro e 12 horas de escuro, regulado por timer automático. Essas condições de temperatura e iluminação estiveram presentes em todas as fases do experimento, exceto durante a fase em que houve exposição ao protocolo de estressores, para a iluminação. 
Manipulação dos sujeitos

Desde dois a cinco dias de vida de todos os sujeitos, a pesagem foi realizada diariamente. Inicialmente, como não era possível a distinção por sexo, todos os sujeitos eram marcados e pesados.

Para a pesagem, a experimentadora e um eventual auxiliar seguiam este procedimento: luvas de látex eram colocadas, e as mãos enluvadas eram esfregadas na maravalha em que os ratos estavam para diminuir a possibilidade de que qualquer cheiro estranho ficasse nos ratos, o que se acreditava poder causar rejeição deles pelas mães. Uma quantidade de maravalha também era colocada na balança durante a pesagem, de forma que os ratos não entravam diretamente em contato com nenhum material que não a própria maravalha onde estavam.

Esse procedimento todo durava aproximadamente 20 minutos para cada caixa, sendo este, portanto, o período máximo que um filhote poderia permanecer diariamente longe de sua mãe. Um fator importante a ser salientado é que esses sujeitos, diferentemente dos sujeitos utilizados nos experimentos sobre CMS realizados no mesmo laboratório aqui citados (Cardoso, 2008; Dolabela, 2004; Rodrigues, 2005; Thomaz, 2001, 2005), foram manipulados diariamente desde muito novos, muito antes do desmame.

Esse fator - manipulação neonatal - será abordado em mais detalhes nos resultados.

Acesso livre a alimento e água (do desmame ao início da privação)

Nesta condição, todos os sujeitos tiveram acesso livre a água e alimento. Seu peso corporal e o consumo desses itens foram aferi- dos diariamente. A fase foi iniciada assim que os sujeitos foram separados das mães (a partir do desmame) e encerrada quando todos atingiram aproximadamente 90 dias de vida, idade considerada adequada para o início do procedimento de privação.

\section{Testes de ingestão e preferência de líquidos}

Para todos os sujeitos do experimento, os testes de ingestão e preferência de líquidos foram realizados semanalmente, a partir do início da privação. Os testes consistiram em expor os sujeitos, na gaiola viveiro, a duas mamadeiras, uma contendo água e outra contendo água com sacarose a $2 \%{ }^{2}$ Após um período de uma hora, as mamadeiras eram retiradas e a quantidade consumida era medida, comparando-se os conteúdos de antes e depois do teste em cada mamadeira (conteúdo restante do disponibilizado inicialmente). A preferência foi calculada dividindo-se a quantidade ingerida de sacarose pela soma da quantidade ingerida de ambos os líquidos (água e água com sacarose) e multiplicando-se o resultado por 100 .

A cada teste, os lados de apresentação das mamadeiras eram alternados. Dessa forma, diminuía-se a possibilidade de que o sujeito preferisse um lado, e não um dos líquidos. Além disso, as garrafas eram sempre colocadas na mesma ordem: primeiramente a da esquerda e, em seguida, a da direita. Dessa forma, também o momento de colocação de cada líquido foi alternado a cada teste.

Esses testes foram realizados antes do início, durante e depois do término do protocolo de estressores. No total, 21 testes foram

\footnotetext{
2 Essa concentração foi utilizada por ter sido verificada por Thomaz (2001, 2005) como a concentração suficiente para que os sujeitos ingerissem preferencialmente sacarose em relação à água.
} 
realizados, sendo 12 antes, seis durante e três depois do término do protocolo.

\section{Protocolo de estressores}

O protocolo de estressores utilizado na presente pesquisa foi similar ao de Willner et al. (1987) e foi composto dos seguintes estressores: (a) inclinação da gaiola (a gaiola viveiro é inclinada a $30^{\circ}$ para trás, permanecendo assim por sete ou 17 horas), (b) luz estroboscópica (uma luz estroboscópica, localizada no chão da sala, que dispara 300 flashes por minuto, era ligada por duas ou sete horas), (c) privação de comida (o alimento era retirado da gaiola, e os sujeitos permaneciam em privação por períodos variados, de 24 a 43 horas), (d) privação de água (a água era retirada da gaiola, e os sujeitos permaneciam em privação por períodos variados, de 17 a 44 horas), (e) gaiola suja (serragem molhada com água era colocada no chão da gaiola, e a gaiola permanecia suja por 17 horas), (f) barulho intermitente (um ruído branco intermitente de 85 decibéis era ligado, permanecendo por três ou cinco horas), (g) agrupamento (dois sujeitos eram colocados em uma mesma gaiola, tanto na gaiola originalmente de um quanto na do outro, ou seja, a cada agrupamento da dupla, a gaiola de um dos dois sujeitos era utilizada, por 17 horas), (h) objeto estranho na gaiola (um objeto de metal redondo de $7 \mathrm{~cm}$ de diâmetro e $1,5 \mathrm{~cm}$ de altura era colocado na gaiola viveiro e deixado por um período de 17 horas), (i) cheiro (um desodorante purificador de ar era colocado na sala, ficando lá por 17 horas. Por tratar-se de um desodorante de duração aproximada de 30 dias, a intensidade do cheiro permanecia por todo o período), (j) iluminação contínua (a luz da sala permanecia acesa por até 19 horas seguidas), (k) garrafa de água vazia (exposição a uma garrafa de água vazia por uma hora, após período de privação de água), (l) acesso restrito à comida (três pelotas de $1 \mathrm{~g}$, espalhadas pela gaiola viveiro do sujeito, sendo disponibilizadas aos sujeitos após um período de privação de comida).

Comparando-se com o protocolo de Willner et al. (1987), apenas o estressor temperatura reduzida (temperatura da sala diminuída para $10^{\circ} \mathrm{C}$ ) não foi utilizado neste experimento, por dificuldades de sua aplicação no biotério do laboratório de realização do presente estudo. Pelo fato de outros estudos como, por exemplo, Thomaz (2001, 2005), Dolabela (2004), Rodrigues (2005) e Cardoso (2008) não terem utilizado esse estressor e, mesmo assim, terem produzido resultados semelhantes aos de Willner et al. (1987), foi considerado que sua retirada do protocolo implementado não traria prejuízos especiais ao presente estudo.

Cada estressor era apresentado por um determinado período de tempo, alternando-se com os outros, em um ciclo de sete dias, durante seis semanas. Em um intervalo entre estressores, as sessões operantes foram realizadas para alguns sujeitos. Os testes de ingestão e preferência por sacarose também ocorreram durante o período de implementação do protocolo de estressores. Os ciclos, bem como momentos de realização de testes e sessões operantes, podem ser visualizados na Tabela 1. A célula sombreada corresponde ao período de realização do teste (uma hora).

\section{Sessões operantes}

Todos os sujeitos que passaram pela condição operante passaram pelo procedimento 


\section{Tabela 1}

Distribuição dos estressores a cada hora do dia, pelos dias da semana, ao longo de uma semana (um ciclo)

\begin{tabular}{|c|c|c|c|c|c|c|c|}
\hline Horas & QUI & SEX & SÁB & DOM & SEG & TER & QUA \\
\hline 1 & $\begin{array}{l}\text { Priv água/ } \\
\text { Iluminação cont }\end{array}$ & $\begin{array}{l}\text { Priv alimento e } \\
\text { água/Objeto estr }\end{array}$ & $\begin{array}{l}\text { Priv alimento/ } \\
\text { Agrupamento }\end{array}$ & Cheiro & $\begin{array}{l}\text { Priv alimento e água/ } \\
\text { Iluminação cont }\end{array}$ & Inclinação & $\begin{array}{l}\text { Priv alimento e } \\
\text { água/Gaiola suja }\end{array}$ \\
\hline 2 & $\begin{array}{l}\text { Priv água/ } \\
\text { Iluminação cont }\end{array}$ & $\begin{array}{l}\text { Priv alimento e } \\
\text { água/Objeto estr }\end{array}$ & $\begin{array}{l}\text { Priv alimento/ } \\
\text { Agrupamento }\end{array}$ & Cheiro & $\begin{array}{l}\text { Priv alimento e água/ } \\
\text { Iluminação cont }\end{array}$ & Inclinação & $\begin{array}{l}\text { Priv alimento e } \\
\text { água/Gaiola suja }\end{array}$ \\
\hline 3 & $\begin{array}{c}\text { Priv água/ } \\
\text { Iluminação cont }\end{array}$ & $\begin{array}{l}\text { Priv alimento e } \\
\text { água/Objeto estr }\end{array}$ & $\begin{array}{l}\text { Priv alimento/ } \\
\text { Agrupamento }\end{array}$ & Cheiro & $\begin{array}{l}\text { Priv alimento e água/ } \\
\text { Iluminação cont }\end{array}$ & Inclinação & $\begin{array}{l}\text { Priv alimento e } \\
\text { água/Gaiola suja }\end{array}$ \\
\hline 4 & $\begin{array}{l}\text { Priv água/ } \\
\text { Iluminação cont }\end{array}$ & $\begin{array}{l}\text { Priv alimento e } \\
\text { água/Objeto estr }\end{array}$ & $\begin{array}{l}\text { Priv alimento/ } \\
\text { Agrupamento }\end{array}$ & Cheiro & $\begin{array}{l}\text { Priv alimento e água/ } \\
\text { Iluminação cont }\end{array}$ & Inclinação & $\begin{array}{l}\text { Priv alimento e } \\
\text { água/Gaiola suja }\end{array}$ \\
\hline 5 & $\begin{array}{l}\text { Priv água/ } \\
\text { Iluminação cont }\end{array}$ & $\begin{array}{l}\text { Priv alimento e } \\
\text { água/Objeto estr }\end{array}$ & $\begin{array}{l}\text { Priv alimento/ } \\
\text { Agrupamento }\end{array}$ & Cheiro & $\begin{array}{l}\text { Priv alimento e água/ } \\
\text { Iluminação cont }\end{array}$ & Inclinação & $\begin{array}{l}\text { Priv alimento e } \\
\text { água/Gaiola suja }\end{array}$ \\
\hline 6 & $\begin{array}{l}\text { Priv água/ } \\
\text { Iluminação cont }\end{array}$ & $\begin{array}{l}\text { Priv alimento e } \\
\text { água/Objeto estr }\end{array}$ & $\begin{array}{l}\text { Priv alimento/ } \\
\text { Agrupamento }\end{array}$ & Cheiro & $\begin{array}{l}\text { Priv alimento e água/ } \\
\text { Iluminação cont }\end{array}$ & Inclinação & $\begin{array}{l}\text { Priv alimento e } \\
\text { água/Gaiola suja }\end{array}$ \\
\hline 7 & $\begin{array}{l}\text { Priv água/ } \\
\text { Iluminação cont }\end{array}$ & $\begin{array}{l}\text { Priv alimento e } \\
\text { água/Objeto estr }\end{array}$ & $\begin{array}{l}\text { Priv alimento/ } \\
\text { Agrupamento }\end{array}$ & Cheiro & $\begin{array}{l}\text { Priv alimento e água/ } \\
\text { Iluminação cont }\end{array}$ & Inclinação & $\begin{array}{l}\text { Priv alimento e } \\
\text { água/Gaiola suja }\end{array}$ \\
\hline 8 & $\begin{array}{l}\text { Priv água/ } \\
\text { Iluminação cont }\end{array}$ & $\begin{array}{l}\text { Priv alimento e } \\
\text { água/Objeto estr }\end{array}$ & $\begin{array}{l}\text { Priv alimento/ } \\
\text { Agrupamento }\end{array}$ & Cheiro & $\begin{array}{l}\text { Priv alimento e água/ } \\
\text { Iluminação cont }\end{array}$ & Inclinação & $\begin{array}{l}\text { Priv alimento e } \\
\text { água/Gaiola suja }\end{array}$ \\
\hline 9 & $\begin{array}{c}\text { Priv água/ } \\
\text { Iluminação cont/ }\end{array}$ & $\begin{array}{l}\text { Priv alimento e } \\
\text { água/Objeto estr }\end{array}$ & $\begin{array}{l}\text { Priv alimento/ } \\
\text { Agrupamento }\end{array}$ & Cheiro & $\begin{array}{l}\text { Priv alimento e água/ } \\
\text { Iluminação cont }\end{array}$ & Inclinação & $\begin{array}{l}\text { Priv alimento e } \\
\text { água/Gaiola suja }\end{array}$ \\
\hline 10 & $\begin{array}{c}\text { Priv água/ } \\
\text { Iluminação cont }\end{array}$ & $\begin{array}{l}\text { Priv alimento e } \\
\text { água/Objeto estr }\end{array}$ & $\begin{array}{l}\text { Priv alimento/ } \\
\text { Agrupamento }\end{array}$ & Cheiro & $\begin{array}{l}\text { Priv alimento e água/ } \\
\text { Iluminação cont }\end{array}$ & Inclinação & $\begin{array}{l}\text { Priv alimento e } \\
\text { água/Gaiola suja }\end{array}$ \\
\hline 11 & $\begin{array}{c}\text { Priv água/Garr } \\
\text { Vazia/ } \\
\text { Luz estrobo }\end{array}$ & $\begin{array}{l}\text { Priv alimento/ } \\
\text { Inclinação }\end{array}$ & $\begin{array}{l}\text { Priv alimento/ } \\
\text { Acesso restrito }\end{array}$ & $\begin{array}{c}\text { Priv } \\
\text { alimento e } \\
\text { água }\end{array}$ & $\begin{array}{l}\text { Priv alimento e água/ } \\
\text { Iluminação cont }\end{array}$ & Luz estrobo & $\begin{array}{l}\text { Priv alimento e } \\
\text { água }\end{array}$ \\
\hline 12 & Luz estrobo & $\begin{array}{l}\text { Priv alimento/ } \\
\text { Inclinação }\end{array}$ & $\begin{array}{l}\text { Priv alimento/ } \\
\text { Acesso restrito }\end{array}$ & $\begin{array}{c}\text { Priv } \\
\text { alimento e } \\
\text { água }\end{array}$ & $\begin{array}{l}\text { Priv alimento e água/ } \\
\text { Iluminação cont }\end{array}$ & Luz estrobo & $\begin{array}{l}\text { Priv alimento e } \\
\text { água }\end{array}$ \\
\hline 13 & Luz estrobo & $\begin{array}{l}\text { Priv alimento/ } \\
\text { Inclinação }\end{array}$ & Barulho interm & $\begin{array}{c}\text { Priv } \\
\text { alimento e } \\
\text { água }\end{array}$ & Operante & - & $\begin{array}{l}\text { Priv alimento e } \\
\text { água }\end{array}$ \\
\hline 14 & Luz estrobo & $\begin{array}{l}\text { Priv alimento/ } \\
\text { Inclinação }\end{array}$ & Barulho interm & $\begin{array}{c}\text { Priv } \\
\text { alimento e } \\
\text { água }\end{array}$ & Operante & - & $\begin{array}{l}\text { Priv alimento e } \\
\text { água }\end{array}$ \\
\hline 15 & Luz estrobo & $\begin{array}{l}\text { Priv alimento/ } \\
\text { Inclinação }\end{array}$ & Barulho interm & $\begin{array}{c}\text { Priv } \\
\text { alimento e } \\
\text { água }\end{array}$ & Operante & - & $\begin{array}{l}\text { Priv alimento e } \\
\text { água }\end{array}$ \\
\hline 16 & Luz estrobo & $\begin{array}{l}\text { Priv alimento/ } \\
\text { Inclinação }\end{array}$ & Barulho interm & $\begin{array}{c}\text { Priv } \\
\text { alimento e } \\
\text { água }\end{array}$ & Operante & $\begin{array}{l}\text { Priv alimento } \\
\text { e água }\end{array}$ & $\begin{array}{l}\text { Priv água/ } \\
\text { Barulho int }\end{array}$ \\
\hline 17 & Luz estrobo & $\begin{array}{l}\text { Priv alimento/ } \\
\text { Inclinação }\end{array}$ & Barulho interm & $\begin{array}{c}\text { Priv } \\
\text { alimento e } \\
\text { água }\end{array}$ & Operante & $\begin{array}{l}\text { Priv alimento } \\
\text { e água }\end{array}$ & $\begin{array}{l}\text { Priv água/ } \\
\text { Barulho int }\end{array}$ \\
\hline
\end{tabular}




\begin{tabular}{|c|c|c|c|c|c|c|c|}
\hline Horas & QUI & SEX & SÁB & DOM & SEG & TER & QUA \\
\hline 18 & $\begin{array}{l}\text { Priv alimento e } \\
\text { água/Objeto estr }\end{array}$ & $\begin{array}{c}\text { Priv alimento/ } \\
\text { Agrupamento }\end{array}$ & Cheiro & $\begin{array}{c}\text { Priv } \\
\text { alimento } \\
\text { e água/ } \\
\text { Iluminação } \\
\text { cont }\end{array}$ & Inclinação & $\begin{array}{c}\text { Priv alimento } \\
\text { e água/Gaiola } \\
\text { suja }\end{array}$ & $\begin{array}{c}\text { Priv água/ } \\
\text { Iluminação cont/ } \\
\text { Barulho int }\end{array}$ \\
\hline 19 & $\begin{array}{l}\text { Priv alimento e } \\
\text { água/Objeto estr }\end{array}$ & $\begin{array}{c}\text { Priv alimento/ } \\
\text { Agrupamento }\end{array}$ & Cheiro & $\begin{array}{c}\text { Priv } \\
\text { alimento } \\
\text { e água/ } \\
\text { Iluminação } \\
\text { cont }\end{array}$ & Inclinação & $\begin{array}{l}\text { Priv alimento } \\
\text { e água/Gaiola } \\
\text { suja }\end{array}$ & $\begin{array}{l}\text { Priv água/ } \\
\text { Iluminação cont }\end{array}$ \\
\hline 20 & $\begin{array}{l}\text { Priv alimento e } \\
\text { água/Objeto estr }\end{array}$ & $\begin{array}{l}\text { Priv alimento/ } \\
\text { Agrupamento }\end{array}$ & Cheiro & $\begin{array}{c}\text { Priv } \\
\text { alimento } \\
\text { e água/ } \\
\text { Iluminação } \\
\text { cont }\end{array}$ & Inclinação & $\begin{array}{c}\text { Priv alimento } \\
\text { e água/Gaiola } \\
\text { suja }\end{array}$ & $\begin{array}{c}\text { Priv água/ } \\
\text { Iluminação cont }\end{array}$ \\
\hline 21 & $\begin{array}{l}\text { Priv alimento e } \\
\text { água/Objeto estr }\end{array}$ & $\begin{array}{l}\text { Priv alimento/ } \\
\text { Agrupamento }\end{array}$ & Cheiro & $\begin{array}{c}\text { Priv } \\
\text { alimento } \\
\text { e água/ } \\
\text { Iluminação } \\
\text { cont }\end{array}$ & Inclinação & $\begin{array}{c}\text { Priv alimento } \\
\text { e água/Gaiola } \\
\text { suja }\end{array}$ & $\begin{array}{l}\text { Priv água/ } \\
\text { Iluminação cont }\end{array}$ \\
\hline 22 & $\begin{array}{l}\text { Priv alimento e } \\
\text { água/Objeto estr }\end{array}$ & $\begin{array}{l}\text { Priv alimento/ } \\
\text { Agrupamento }\end{array}$ & Cheiro & $\begin{array}{c}\text { Priv } \\
\text { alimento } \\
\text { e água/ } \\
\text { Iluminação } \\
\text { cont }\end{array}$ & Inclinação & $\begin{array}{l}\text { Priv alimento } \\
\text { e água/Gaiola } \\
\text { suja }\end{array}$ & $\begin{array}{c}\text { Priv água/ } \\
\text { Iluminação cont }\end{array}$ \\
\hline 23 & $\begin{array}{l}\text { Priv alimento e } \\
\text { água/Objeto estr }\end{array}$ & $\begin{array}{l}\text { Priv alimento/ } \\
\text { Agrupamento }\end{array}$ & Cheiro & $\begin{array}{c}\text { Priv } \\
\text { alimento } \\
\text { e água/ } \\
\text { Iluminação } \\
\text { cont }\end{array}$ & Inclinação & $\begin{array}{c}\text { Priv alimento } \\
\text { e água/Gaiola } \\
\text { suja }\end{array}$ & $\begin{array}{l}\text { Priv água/ } \\
\text { Iluminação cont }\end{array}$ \\
\hline 24 & $\begin{array}{l}\text { Priv alimento e } \\
\text { água/Objeto estr }\end{array}$ & $\begin{array}{l}\text { Priv alimento/ } \\
\text { Agrupamento }\end{array}$ & Cheiro & $\begin{array}{c}\text { Priv } \\
\text { alimento } \\
\text { e água/ } \\
\text { Iluminação } \\
\text { cont }\end{array}$ & Inclinação & $\begin{array}{l}\text { Priv alimento } \\
\text { e água/Gaiola } \\
\text { suja }\end{array}$ & $\begin{array}{l}\text { Priv água/ } \\
\text { Iluminação cont }\end{array}$ \\
\hline
\end{tabular}

aqui denominado "variação e seleção". Nesse procedimento, os sujeitos eram colocados na caixa experimental, e o equipamento ficava ligado em modo automático, de modo que qualquer resposta de pressão à barra ativava o mecanismo e, dessa forma, produzia o reforço. Nessa fase, foi utilizada água como estímulo reforçador, e a caixa era equipada com apenas um conjunto barra/bebedouro. O regime de privação a que os sujeitos que passaram pelas sessões operantes eram submetidos será posteriormente descrito.

Após a aquisição da resposta de pressão à barra, sessões de fortalecimento da resposta foram realizadas com cada sujeito, até que todos obtivessem o mesmo número de reforçadores nessa condição (180 reforçadores).

Todas as sessões operantes foram realizadas em um horário específico, e todos os sujeitos eram transportados para a sala expe- 
rimental, mesmo os que não passavam pelas sessões, a fim de isolar a interferência de variáveis como transporte e local de alojamento durante esses períodos. A ordem de transporte dos sujeitos e de realização da sessão operante para cada um foi randomizada a cada semana.

O esquema de reforçamento utilizado foi idêntico ao de Thomaz (2001, 2005), Dolabela (2004) e Rodrigues (2005). Após o fortalecimento da resposta em uma barra, a segunda barra foi colocada na caixa, sendo, então, dispensada para pressões nessa segunda barra a água com sacarose como estímulo reforçador. $\mathrm{O}$ esquema de reforçamento contínuo para cada uma das barras foi gradualmente aumentado de CRF para FR2 e, depois, para FR4. Além disso, a quantidade média de sacarose consumida pelos sujeitos que passavam por sessões operantes era disponibilizada para os demais sujeitos, para que a ingestão de sacarose nessas condições, em si, não se tornasse uma variável possivelmente interferente, à qual apenas alguns dos sujeitos tivessem sido expostos.

A cada duas sessões consecutivas em que houvesse preferência por uma das barras, elas eram alternadas na sessão seguinte. Assim, quando um sujeito respondia com frequência mais alta em uma das barras por duas sessões, na sessão subsequente era feita a alternação, ou seja, o reforço que era liberado para pressões em uma delas passava a ser liberado para pressões na outra. Após uma alternação em que o sujeito ficasse duas sessões com essa nova posição das barras, respondendo com preferência a uma delas, a razão era aumentada.

As sessões foram realizadas semanalmente, no horário em que não havia nenhum estressor programado (ver Tabela 1). Cada sessão teve a duração de uma hora ou 200 reforços, o que ocorresse primeiro.

\section{Delineamento experimental}

Três arranjos diferentes de condições experimentais foram realizados no presente estudo. Todos os três arranjos têm em comum a exposição dos sujeitos às três primeiras condições descritas; eles diferiam entre si com relação ao protocolo de estressores ao qual os sujeitos foram expostos, ao regime de privação implementado e à realização ou não de sessões operantes; essas diferenças é que caracterizam os diferentes grupos de sujeitos experimentais. Os arranjos, então, podem ser assim denominados e descritos:

a) Protocolo completo. Neste arranjo, seis sujeitos foram submetidos ao protocolo de estressores supradescrito. Desses seis sujeitos, três passaram também por sessões operantes. Com aproximadamente 90 dias de vida, após passarem pelas condições preparatória e de acesso livre a alimento e água, para os seis sujeitos, dois períodos de privação semanal (de água e alimento) estiveram em vigor: 23 horas antes dos testes e 26 horas antes das sessões operantes (este período esteve em vigor para todos os sujeitos, mesmo para os que não passariam pelas sessões operantes); isso ocorreu durante 12 semanas anteriores ao protocolo e durante as quatro semanas após seu término. Durante o período de exposição ao protocolo, além desses períodos de privação, os sujeitos foram submetidos aos demais períodos de privação previstos no protocolo, assim como aos demais estressores (ver Tabelas 1 e 2). 
b) Protocolo incompleto (sem privação). Neste arranjo, quatro sujeitos foram submetidos, com aproximadamente 169 dias de vida, ao protocolo de estressores supradescrito, com exceção de três estressores: privação de alimento, privação de água e acesso restrito a alimento. Dos quatro sujeitos nessa condição, um passou também por sessões operantes. (Por ser proposto que o sujeito passasse por sessões operantes sem nenhuma privação prévia, esta condição teve apenas um sujeito a título exploratório.) Para três desses sujeitos, anteriormente ao início do protocolo, nenhuma condição específica esteve prevista, além das três primeiras descritas (preparatória, acesso livre e testes). Para o quarto sujeito, além das condições citadas, foram realizadas sessões operantes, no mesmo período em que tais sessões ocorriam para os sujeitos de outros arranjos que também passavam pelas sessões. Mesmo passando por sessões operantes, esse sujeito nunca foi submetido a nenhuma condição de privação de água ou de alimento. Não foi planejada nenhuma condição para ocupar os períodos do protocolo destinados à privação de água e/ou de alimento ou ao acesso restrito a eles. Se observada a Tabela 1, é possível identificar a ordem de apresentação dos estressores (para esses sujeitos, com exceção dos estressores citados) e os momentos de realização dos testes (célula sombreada) e das sessões operantes para o sujeito que também passou por elas.

c) Apenas privação. Para os seis sujeitos deste arranjo, além das condições iniciais (preparatória e acesso livre), os períodos de privação de água e alimento prévios ao operante e aos testes de ingestão e preferência também foram realizados a partir de aproximadamente 90 dias de vida dos sujeitos. Então, também para esses sujeitos, durante as 12 semanas anteriores ao protocolo e durante as quatro semanas após seu término, dois períodos de privação semanal estiveram em vigor: 23 horas antes dos testes e 26 horas antes das sessões operantes. Com aproximadamente 169 dias de vida, os seis sujeitos foram submetidos apenas à privação de água e de alimento do protocolo de estressores supradescrito. Portanto, passaram por todos os períodos de privação, tanto de água quanto de alimento, previstos no protocolo, mas não pelo restante dos estressores. A ordem de exposição a cada período de privação e a duração de cada um deles podem ser vistas na Tabela 1, já que esses períodos corresponderam a períodos de privação idênticos ao do protocolo. Para os demais períodos, em que outros estressores estariam em vigor, nenhuma condição foi programada. Desses seis sujeitos, três passaram, também, por sessões operantes.

Dada a variedade de condições e de arranjo de condições e, nesse caso, de grupos experimentais correspondentes, uma nomeação foi proposta para os sujeitos submetidos a cada um dos arranjos, para tornar o relato dos resultados mais claro.

Os sujeitos do primeiro arranjo, protocolo completo, foram nomeados "protocolo completo com operante" (PCO) ou apenas "protocolo completo" (PC). Os sujeitos do arranjo apenas privação foram nomeados “apenas privação com operante" (APO) ou "apenas privação" (AP). Os sujeitos do arranjo protocolo incompleto, da mesma forma, "protocolo incompleto com operante" (PIO) ou apenas "protocolo incompleto" 
(PI). A Tabela 2 sumariza as condições ex- jeitos, bem como a nomenclatura utilizada perimentais a que foram submetidos os su- para eles.

Tabela 2

Divisão dos sujeitos pelos arranjos das condições experimentais

\begin{tabular}{|c|c|c|c|c|c|c|}
\hline & \multirow{4}{*}{ Sujeitos } & \multicolumn{5}{|c|}{ Condições } \\
\hline & & 1 & 2 & 3 & 4 & 5 \\
\hline & & Preparatória & $\begin{array}{l}\text { Acesso livre } \\
\text { alimento e } \\
\text { água }\end{array}$ & $\begin{array}{l}\text { Início testes (com } \\
\text { ou sem privação } \\
\text { antes }-23 \mathrm{~h} \text { ) } \\
\text { Início sessões } \\
\text { operantes (com } \\
\text { ou sem privação } \\
\text { antes }-26 \text { h) }\end{array}$ & $\begin{array}{l}\text { Exposição a } \\
\text { estressores }\end{array}$ & $\begin{array}{l}\text { Pós- } \\
\text { exposição }\end{array}$ \\
\hline & & & & 12 semanas & 6 semanas & 4 semanas \\
\hline \multirow{3}{*}{ Arranjo a } & Sujeito PCO1 & & & & & \\
\hline & Sujeito PCO2 & $\operatorname{Sim}$ & Sim & $\begin{array}{c}\text { Testes com privação } \\
\text { Operante com } \\
\text { privação }\end{array}$ & $\begin{array}{l}\text { Protocolo } \\
\text { completo }\end{array}$ & $\begin{array}{l}\text { Testes e } \\
\text { operante } \\
\text { idem } 3\end{array}$ \\
\hline & Sujeito PCO3 & & & & & \\
\hline \multirow{3}{*}{ Arranjo a } & Sujeito PC1 & & & & & \\
\hline & Sujeito PC2 & $\operatorname{Sim}$ & $\operatorname{Sim}$ & $\begin{array}{c}\text { Testes com privação } \\
\text { Sem operante }\end{array}$ & $\begin{array}{l}\text { Protocolo } \\
\text { completo }\end{array}$ & Testes idem 3 \\
\hline & Sujeito PC3 & & & & & \\
\hline \multirow[t]{2}{*}{ Arranjo b } & $\begin{array}{l}\text { Sujeito PI1 } \\
\text { Sujeito PI2 }\end{array}$ & $\operatorname{Sim}$ & $\operatorname{Sim}$ & $\begin{array}{l}\text { Testes sem privação } \\
\text { Sem operante }\end{array}$ & $\begin{array}{c}\text { Protocolo } \\
\text { incompleto } \\
\text { (sem privação) }\end{array}$ & Testes idem 3 \\
\hline & Sujeito PI3 & & & & & \\
\hline Arranjo b & Sujeito PIO & Sim & Sim & $\begin{array}{c}\text { Testes sem privação } \\
\text { Operante sem } \\
\text { privação }\end{array}$ & $\begin{array}{c}\text { Protocolo } \\
\text { incompleto } \\
\text { (sem privação) }\end{array}$ & $\begin{array}{c}\text { Testes e } \\
\text { operante } \\
\text { idem } 3 \\
\end{array}$ \\
\hline \multirow[t]{2}{*}{ Arranjo c } & Sujeito APO1 & $\operatorname{Sim}$ & Sim & $\begin{array}{c}\text { Testes com privação } \\
\text { Operante com } \\
\text { privação }\end{array}$ & $\begin{array}{c}\text { Apenas privação } \\
\text { prevista no } \\
\text { protocolo }\end{array}$ & $\begin{array}{l}\text { Testes e } \\
\text { operante } \\
\text { idem } 3\end{array}$ \\
\hline & Sujeito APO3 & & & & & \\
\hline \multirow[t]{2}{*}{ Arranjo c } & Sujeito AP1 & $\operatorname{Sim}$ & $\operatorname{Sim}$ & $\begin{array}{c}\text { Testes com privação } \\
\text { Sem operante }\end{array}$ & $\begin{array}{c}\text { Apenas privação } \\
\text { prevista no } \\
\text { protocolo }\end{array}$ & Testes idem 3 \\
\hline & Sujeito AP3 & & & & & \\
\hline
\end{tabular}




\section{Resultados}

Para analisar os dados obtidos, foram levadas em conta as três variáveis independentes aqui manipuladas: (a) o protocolo de estressores, (b) o comportamento operante e (c) a privação, bem como sua interação. Serão apresentadas, para avaliar os efeitos de tais variáveis independentes, as alterações na ingestão e preferência por sacarose apresentadas pelos sujeitos, por ser essa a medida comum utilizada nos estudos previamente relatados.

Apenas privação (com e sem condição operante)

Os sujeitos do grupo apenas privação foram distribuídos em sujeitos expostos à condição operante (APO1, APO2, APO3) e sujeitos não expostos a essa condição (AP1, AP2, AP3). Esses sujeitos passaram por duas condições de privação, durante todo o experimento. Durante 12 semanas, na primei- ra condição, os sujeitos foram submetidos a dois períodos de privação semanais. Depois, na segunda condição, durante seis semanas, a uma alteração no esquema de privação, tornando-a idêntica à do protocolo de estressores. Ou seja, mesmo não sendo submetidos a nenhum dos outros estímulos programados no protocolo (ex., agrupamento, iluminação contínua, objeto estranho na gaiola), as privações de água e alimento previstas nele foram estipuladas para esses sujeitos (ver Tabela 1). Concluída essa condição, novamente os dois períodos de privação semanais vigoraram por três semanas (volta à primeira condição de privação) e, então, o experimento foi encerrado. Para visualizar melhor as duas condições de privação, o total de horas semanais de cada período de privação, bem como o intervalo entre cada período, para as duas condições de privação, está sumarizado na Tabela 3 .

Tabela 3

Total de horas semanais dos períodos de privação a que os sujeitos eram submetidos e intervalo entre os períodos, nas duas condições de privação

\begin{tabular}{|c|c|c|c|c|c|c|}
\hline & \multicolumn{3}{|c|}{$\begin{array}{c}\text { Antes e depois } \\
\text { (primeira condição) }\end{array}$} & \multicolumn{3}{|c|}{$\begin{array}{c}\text { Durante } \\
\text { (segunda condição) }\end{array}$} \\
\hline & $\begin{array}{c}\text { Total de } \\
\text { horas } \\
\text { semanais }\end{array}$ & Períodos & $\begin{array}{l}\text { Intervalo } \\
\text { entre os } \\
\text { períodos }\end{array}$ & $\begin{array}{c}\text { Total de } \\
\text { horas } \\
\text { semanais }\end{array}$ & Períodos & $\begin{array}{l}\text { Intervalo } \\
\text { entre os } \\
\text { períodos }\end{array}$ \\
\hline $\begin{array}{l}\text { Privação } \\
\text { água }\end{array}$ & 49 horas & $\begin{array}{c}2 \text { períodos } \\
\text { (23 e } 26 \\
\text { horas) }\end{array}$ & 141 horas & 86 horas & $\begin{array}{l}4 \text { períodos } \\
(23,20,17, \\
\text { e } 26 \text { horas })\end{array}$ & $\begin{array}{l}1 \text { (teste) } \\
6,48 \text { e } 27 \\
\quad \text { horas }\end{array}$ \\
\hline $\begin{array}{l}\text { Privação } \\
\text { alimento }\end{array}$ & 49 horas & $\begin{array}{c}2 \text { períodos } \\
\text { (23 e } 26 \\
\text { horas) }\end{array}$ & 141 horas & 92 horas & $\begin{array}{c}3 \text { períodos } \\
\text { (24, } 43 \text { e } \\
26 \text { horas) }\end{array}$ & $\begin{array}{c}26,22 \text { e } 27 \\
\text { horas }\end{array}$ \\
\hline
\end{tabular}


Em relação à ingestão e preferência por sacarose, seria investigada aqui a possibilidade de que não o protocolo completo, mas apenas a privação, isolada dos demais estressores, fosse responsável pela alteração que é geralmente observada em sujeitos que são submetidos a ele. Conforme levantado por Matthews et al. (1995) e Forbes et al. (1996), a diminuição de ingestão de sacarose observada no CMS seria secundária à perda de peso, isto é, essa diminuição seria devida a uma diminuição na massa corpórea dos sujeitos (que ocorre devido à privação), e não a alterações no valor desses estímulos (produção de anedonia - medida pela diminuição na ingestão de substância doce). Então, se o peso fosse reduzido (por meio da privação), mesmo não sendo submetidos aos demais estressores, os sujeitos apresentariam redução, também, da quantidade de sacarose ingerida.

Os resultados dos testes de ingestão e preferência para os sujeitos dos grupos APO e AP são apresentados na Figura 1. Foram realizados, com esses sujeitos, 12 testes na primeira condição de privação, seis testes na segunda condição de privação e três testes quando houve retorno à primeira condição de privação.

É possível perceber, na Figura 1, que a ingestão de sacarose, ao longo do experimento, não parece sofrer alterações pelo aumento da privação na segunda condição de privação. Para os sujeitos APO1 e AP3, há um aumento na primeira semana desse período; para os sujeitos APO3, AP1 e AP2, há uma diminuição; a ingestão para o sujeito APO2 se mantém no primeiro teste da segunda condição de privação (teste 13), diminuindo logo em seguida e aumentando novamente.
Apenas um resultado parece consistente para quase todos os sujeitos (com exceção do sujeito APO1): após a volta à primeira condição de privação, a ingestão absoluta de sacarose cai para os sujeitos do grupo apenas privação, mantendo-se, mesmo assim, a preferência. Para o sujeito APO1, essa queda é notada apenas no primeiro teste após a volta à primeira condição de privação, enquanto para os sujeitos APO2 e APO3 ela ocorre também nos testes subsequentes a esse. Não há como afirmar, porém, que esses resultados sejam devidos ao regime de privação em vigor nesse momento: para todos os sujeitos, as alterações observadas não diferem de maneira importante dos valores de ingestão observados anteriormente.

Portanto, não há como afirmar consistentemente a existência de relação entre o regime de privação e a ingestão de sacarose, da mesma forma que afirmam Matthews et al. (1995) e Forbes et al. (1996), já que, mesmo havendo submissão dos sujeitos às privações do protocolo, não são observadas diferenças na ingestão de sacarose por conta dessa variável (afirmada pelos autores como variável crítica na produção de diminuição de ingestão e preferência de sacarose, pela produção de diminuição do peso).

Outra observação a ser feita com relação ao resultado nos testes de ingestão e preferência, para os sujeitos dos grupos apenas privação, se refere a uma possível diferença identificada entre o grupo com operante (APO) e o grupo sem essa condição (AP). Para o grupo APO, a curva de ingestão de sacarose parece demonstrar ligeira aceleração, como se a ingestão fosse aumentando ao longo do tempo. Para o grupo AP, no entanto, essa aceleração não é notada, sendo possível constatar fenô- 
APO1

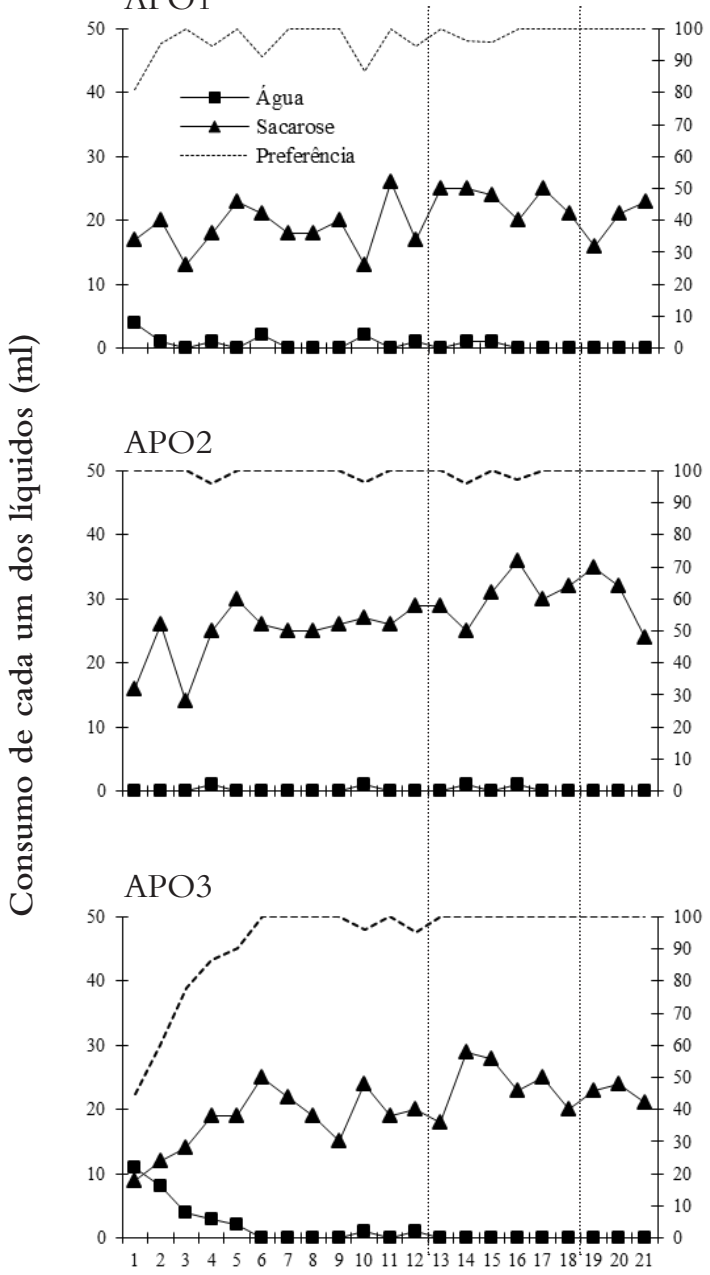

AP1

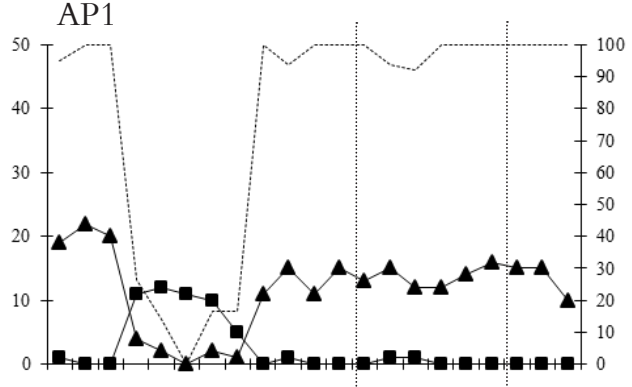

AP2

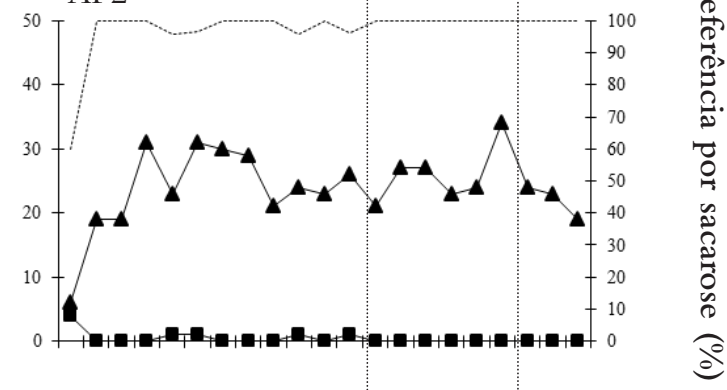

AP3

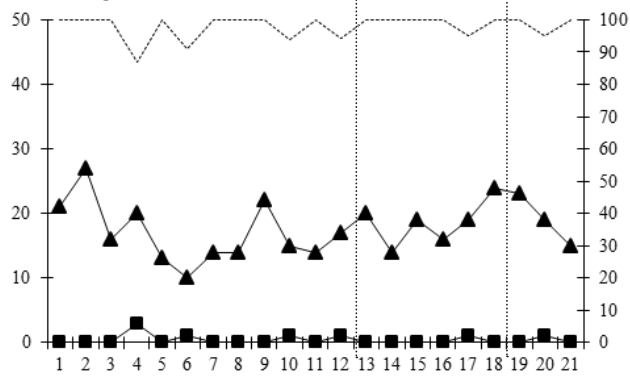

Semanas

Figura 1. Ingestão e preferência de líquidos aferidos nos testes realizados semanalmente, para os sujeitos dos grupos APO e AP. As linhas verticais indicam, respectivamente, início e fim da segunda condição de privação.

meno semelhante apenas para o sujeito AP2, porém em menor escala. Dessa forma, parece que as sessões operantes, de alguma forma, influenciaram a ingestão de sacarose ao longo do experimento. A Tabela 4, que apresenta o cálculo da média de ingestão para cada sujeito nas semanas 2, 3 e 4 (semanas iniciais) e nas semanas 19, 20 e 21 (três últimas semanas), demonstra esse aumento de ingestão para os su- jeitos do grupo APO ao longo do experimento. O primeiro teste foi excluído do cálculo por ser considerado um teste de adaptação dos sujeitos aos líquidos e ao procedimento.

Na Tabela 4, é possível verificar que, para os sujeitos APO, a ingestão de sacarose é nitidamente maior ao final do experimento do que no início. Para os sujeitos do grupo AP, a ingestão média nos testes iniciais difere mui- 
Tabela 4

Média de ingestão de sacarose nos testes de ingestão e preferência 2, 3 e 4 e nos testes 19,20 e 21 para os sujeitos dos grupos APO e AP

\begin{tabular}{lcc}
\hline \multirow{2}{*}{ Sujeitos } & $\begin{array}{c}\text { Testes 2, } \\
\text { 3 e 4 }\end{array}$ & $\begin{array}{c}\text { Testes 19, } \\
\text { 20 e 21 }\end{array}$ \\
\cline { 2 - 3 } & \multicolumn{2}{c}{ Média } \\
\hline APO1 & 17 & 20 \\
APO2 & 21,67 & 30,33 \\
APO3 & 15 & 22,67 \\
AP1 & 15,33 & 13,33 \\
AP2 & 23 & 22 \\
AP3 & 21 & 19 \\
\hline
\end{tabular}

to pouco da ingestão média nos testes finais (apenas $1 \mathrm{ml}$ ).

É possível concluir que, com relação aos grupos apenas privação, os resultados encontrados nos testes não demonstram haver relação entre esta e a diminuição na ingestão e/ou preferência por sacarose, havendo diferença apenas entre os sujeitos que passaram por sessões operantes e os sujeitos que não passaram por essa condição.

Protocolo incompleto (com e sem condição operante)

Os sujeitos do grupo protocolo incompleto (PI1, PI2, PI3 e PIO) passaram por todos os estressores previstos no protocolo, exceto as privações de água e alimento. Portanto, antes e depois da implementação do protocolo, nenhuma condição específica esteve prevista, a não ser os testes de ingestão e preferência por sacarose e as sessões operantes (para um dos sujeitos). Com esse grupo de sujeitos, mais uma vez a investigação do papel da privação no conjunto de estressores foi proposta.

$\mathrm{Na}$ Figura 2, são apresentados os resultados dos testes de ingestão e preferência de líquidos para os sujeitos dos grupos PI (protocolo incompleto) e PIO (protocolo incompleto com operante).

Como é possível observar na Figura 2, a preferência por sacarose, para os quatro sujeitos, se mantém alta durante todo o experimento.

Há, no entanto, para os três sujeitos do grupo PI, oscilações notáveis na preferência por sacarose (linha pontilhada) que são observadas justamente no período de exposição ao protocolo (principalmente para o sujeito PI3). Isso ocorre porque parece haver aumento na ingestão de água nos testes durante o protocolo.

A mesma coisa ocorre com o sujeito PIO, só que em menor proporção: há queda na preferência durante esse período, mas ela se mantém no mesmo patamar, que está acima do ponto mais baixo atingido antes.

A ingestão de sacarose, para os sujeitos do grupo protocolo incompleto, é, em média, muito menor $(10 \mathrm{ml})$ do que para os sujeitos dos demais grupos, que sofreram algum tipo de restrição hídrica e alimentar $(21 \mathrm{ml})$. Essa diferença pode, portanto, ser atribuída à privação a que os demais sujeitos são submetidos.

Também para esse grupo, parece haver diferenças entre os sujeitos que não passaram por sessões operantes (PI) e o que passou por essa condição (PIO). De maneira geral, a ingestão dos sujeitos PI1 e PIO apresenta uma tendência de aumento ao longo do experimento. Porém, ela é mais nítida para o último 
PI1

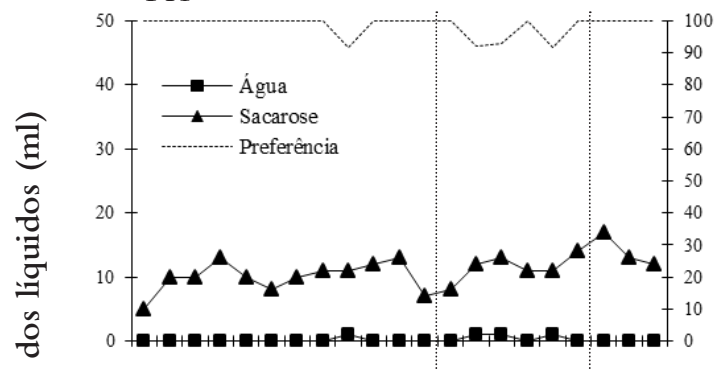

PI3

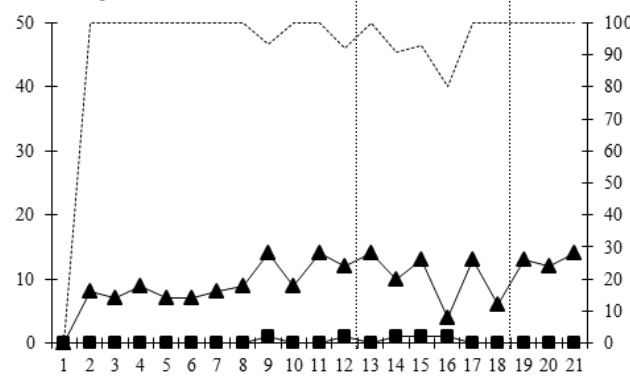

PI2
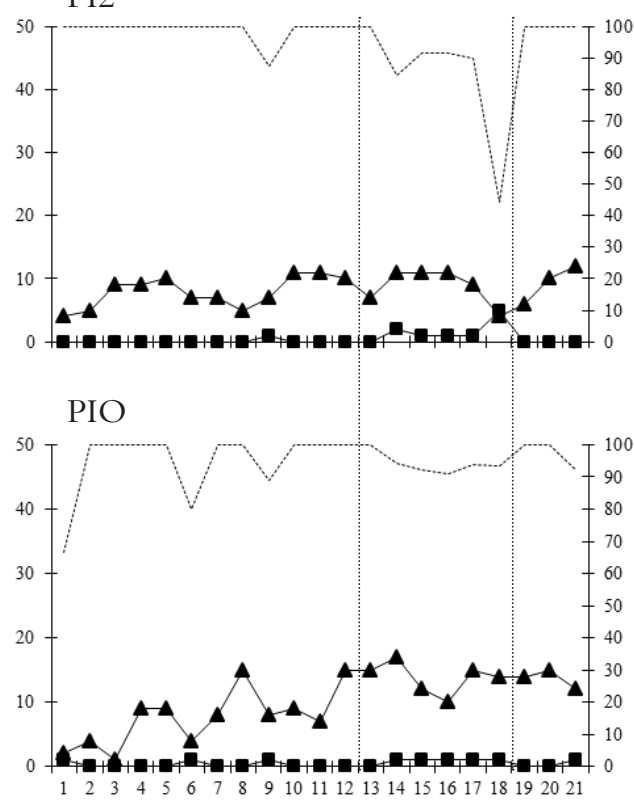

Semanas

Figura 2. Ingestão e preferência de líquidos aferidos nos testes realizados semanalmente, para os sujeitos PI1, PI2, PI3 e PIO. As linhas verticais indicam, respectivamente, início e fim do protocolo de estressores.

(sujeito que passou por sessões operantes). Dessa forma, é possível afirmar que as sessões operantes podem ter sido responsáveis pela produção de diferenças entre os sujeitos, já que era a única condição que diferiu entre os sujeitos. Mesmo assim, essa diferença se mostrou pequena, já que a ingestão final de sacarose (por exemplo, a do último teste) pareceu não diferir entre os sujeitos.

Portanto, com relação à condição de protocolo incompleto, pode-se afirmar que é possível identificar alterações na medida ingestão e preferência pela submissão dos sujeitos ao protocolo, mesmo que sem a privação. Mesmo que pequenas, as alterações são visíveis. Mais uma vez, foi encontrado o aumento na ingestão da sacarose ao longo do tempo, conforme observado para alguns sujeitos da condição de apenas privação. Para esse grupo, também, ela pareceu ter relação com a exposição dos sujeitos à condição operante: esse aumento foi maior para o sujeito PIO (mesmo que apenas sutilmente).

Protocolo completo (com e sem condição operante)

Os sujeitos do grupo protocolo completo passaram por todo o conjunto de estressores, inclusive as privações de alimento e água. Dos seis sujeitos nessa condição, três passaram pelas sessões operantes ao longo do experimento (PCO1, PCO2, PCO3) e três deles não passaram por essas sessões (PC1, PC2, PC3).

Anteriormente ao início do protocolo, os sujeitos dos grupos PCO e PC também passaram pela primeira condição de privação, idêntica a que foi imposta aos sujeitos dos grupos APO e AP. Dois períodos de privação semanais ocorriam, anteriormente às sessões operantes e aos testes de ingestão e preferência (ver Tabela 3). 
Para todos os sujeitos dos grupos $\mathrm{PCO}$ e PC (protocolo completo com e sem operante, respectivamente), é possível observar que os sujeitos apresentam preferência por sacarose durante todo o experimento, o que pode ser visto notando-se, na Figura 3, que a linha pontilhada permanece sempre próxima ao valor $100 \%$.

Como também é possível observar na Figura 3, há diferenças entre os sujeitos que

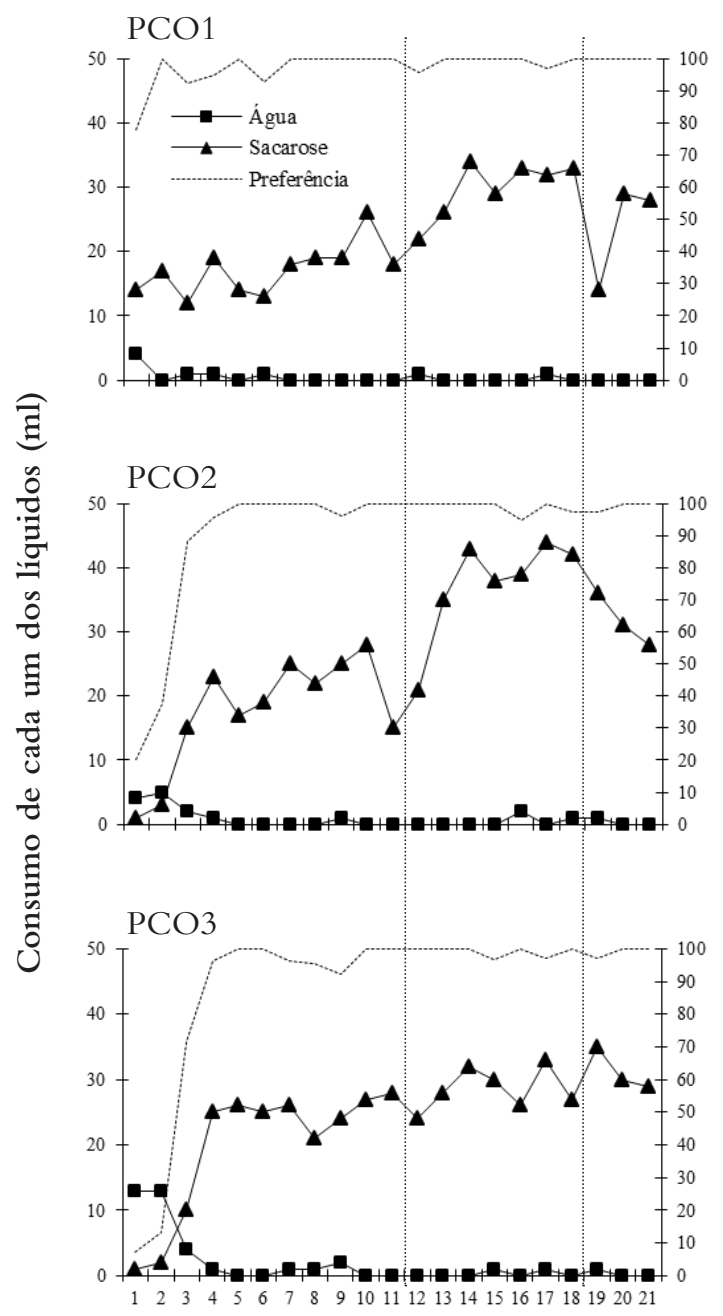

passaram por sessões operantes e os que não passaram por essa condição. Para a ingestão de sacarose, nota-se que há uma tendência de aumento ao longo do experimento para os sujeitos do grupo PCO, ocorrendo isso, também, apenas para o sujeito PC1, inclusive durante o período de estressores. Comparando-se os valores de sacarose ingeridos na semana $1 \mathrm{com}$ os valores consumidos na semana 13, para o sujeito PCO1, isso fica claro: $14 \mathrm{ml}$
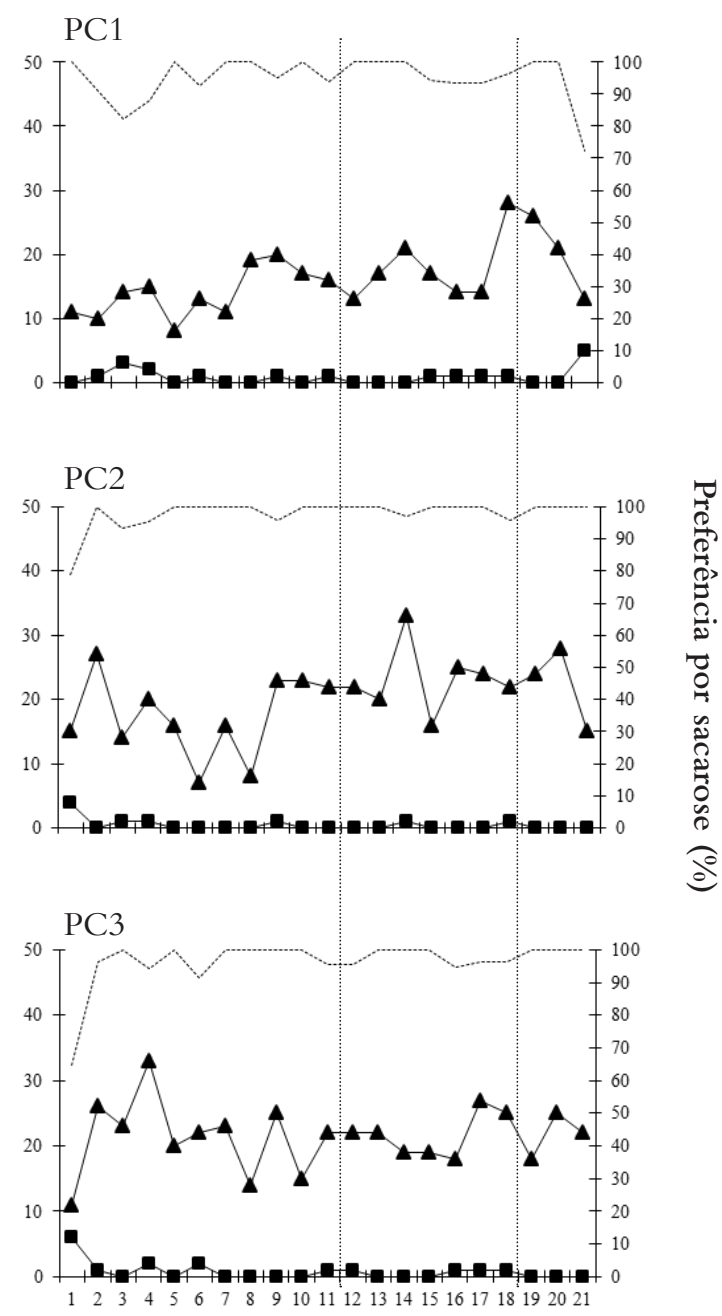

Figura 3. Ingestão e preferência de líquidos aferidos nos testes realizados semanalmente, para os sujeitos PCO1, PCO2, PCO3, PC1, PC2 e PC3. As linhas verticais indicam, respectivamente, início e fim do protocolo de estressores. 
e $26 \mathrm{ml}$. Na semana 1, o sujeito estava sendo submetido à primeira condição de privação; na semana 13, ao protocolo de estressores. Essa diferença pode ser devida a alguns fatores, como a submissão desses sujeitos às sessões operantes e sua maior exposição à sacarose, conforme discutido anteriormente.

A respeito da relação entre privação (diminuição de peso) e diminuição na ingestão, esse grupo também não apresenta o que foi descrito por Matthews et al. (1995) e Forbes et al. (1996). Para esse grupo (assim como para os sujeitos dos grupos submetidos apenas à privação), é observado que o peso dos sujeitos diminui no período de exposição ao protocolo. No entanto, a ingestão de sacarose, nesse mesmo período, aumenta. Esse aumento é mais nítido para os sujeitos do grupo $\mathrm{PCO}$, ocorrendo também, mais nitidamente ao final do protocolo, para os sujeitos PC1 e PC3.

Portanto, é possível concluir que, para os sujeitos que passaram pelo protocolo de estressores completo, não houve diminuição na ingestão e preferência por sacarose durante esse período. Também para os sujeitos que passaram por essa condição, houve diferenças entre sujeitos expostos a sessões operantes e sujeitos que não passaram por elas. Para os primeiros, pareceu haver aumento progressivo na quantidade de sacarose ingerida a cada teste. Com relação à medida de peso relativo à ingestão, não foi encontrada a relação reportada por Matthews et al. (1995) e Forbes et al. (1996).

\section{Discussão}

Os aspectos investigados no presente estudo podem ser assim descritos: a) Qual o papel da privação no conjunto de estressores? Ela é fundamental para que as alterações geralmente observadas de diminuição na ingestão e preferência de líquidos ocorram?

b) Qual o papel do desempenho operante, quando os sujeitos passam também por essa situação, ou seja, se passam também por essa condição, os sujeitos apresentam diferenças com relação àqueles que não passam por ela?

Para isso, algumas manipulações foram propostas. Em primeiro lugar, isolou-se a privação como variável independente. Três grupos de sujeitos foram formados: um que foi exposto à privação, isoladamente; outro que foi exposto à privação, em conjunto com os demais estressores; e, finalmente, outro, que foi exposto a todos os outros estressores, com exceção justamente da privação. Para os três grupos, uma parte dos sujeitos foi também submetida às sessões operantes. Dessa forma, a influência dessa condição nos efeitos previstos do protocolo (ou, no caso, da privação ou do restante do conjunto de estressores) poderia ser avaliada.

Para os sujeitos que foram submetidos apenas à privação (grupos APO e AP), com relação aos testes de ingestão e preferência por sacarose, a privação não demonstrou ter influências nesses resultados, visto que as diferentes condições de privação a que os sujeitos foram submetidos não produziram diferenças na ingestão e preferência apresentada nos testes. Foi observada diferença entre os sujeitos privados que passaram por sessões operantes e os sujeitos privados que não passaram por essa condição. Os primeiros aumentaram a quantidade de sacarose ingerida, com o passar dos testes (ver Figura 1 e Tabela 4). 
Para os sujeitos que passaram pelo protocolo incompleto (sem privação), pequenas alterações foram encontradas com relação à ingestão de líquidos e preferência por sacarose. Foi encontrado o aumento na ingestão de sacarose ao longo do tempo para esses sujeitos, maior para o sujeito PIO, que também passou por sessões operantes. No entanto, não há clara diminuição na ingestão e preferência pela submissão aos demais estressores do protocolo (sem as privações de água e alimento).

Para os sujeitos submetidos ao protocolo completo, nos testes de ingestão e preferência, não houve alteração pela submissão dos sujeitos ao protocolo completo. Para esses sujeitos, assim como para os demais grupos, foi observada maior ingestão de sacarose para os sujeitos que passaram também por sessões operantes.

Levando-se em conta os resultados do presente experimento, uma primeira afirmação pode ser feita: os sujeitos não apresentaram as modificações na ingestão e preferência por sacarose que foram apresentadas pelos sujeitos dos experimentos de Willner et al. (1987), Thomaz (2001, 2005), Dolabela (2004), Rodrigues (2005) e Cardoso (2008). Nesses estudos, todos os sujeitos submetidos ao protocolo de estressores apresentaram diminuição na ingestão e preferência de sacarose. No primeiro estudo, essa diminuição foi revertida pela aplicação de antidepressivos aos sujeitos; nos outros, pela submissão dos sujeitos às sessões operantes.

Os resultados do presente estudo indicam que houve alguma diferença entre os resultados da presente pesquisa e os resultados de Thomaz (2001, 2005), Dolabela (2004), Rodrigues (2005) e Cardoso (2008). Alguma variável aqui presente, que não esteja presente nos outros estudos, pode ter produzido as diferenças entre os resultados. Uma primeira hipótese é a de que essa variável tenha sido a manipulação neonatal.

Conforme descrito no procedimento deste estudo, os sujeitos foram pesados desde aproximadamente dois dias de vida. Foram, portanto, manipulados deste esse momento.

Silveira et al. (2004), Silveira et al. (2008) e Michaels e Holtzman (2006), em artigos sobre a manipulação neonatal, concluíram que esta pode ser considerada uma variável que produz alterações no comportamento de sujeitos na idade adulta, com relação principalmente ao consumo de substâncias doces (aumentando esse consumo). Para eles, a manipulação pode ser considerada um estressor, e passar por essa situação alteraria o valor de alguns estímulos. Essa alteração seria verificada medindo-se o consumo desses estímulos para sujeitos que passassem e sujeitos que não passassem por tal situação, já adultos. Para os sujeitos que passavam pela manipulação, o consumo de substância doce na fase adulta se mostrava maior do que para os sujeitos que não passavam por ela. Porém, em seus estudos, essas alterações ocorreram apenas com relação ao consumo de substâncias doces sólidas, e não com relação ao consumo de substâncias doces líquidas, já que foi utilizada apenas a substância sólida. No presente estudo, no entanto, a sacarose utilizada era dissolvida em água (concentração de $2 \%$ ), tendo sido, mesmo assim, encontrado resultado similar ao relatado por eles.

Portanto, a manipulação neonatal, no presente experimento, pode ter sido responsável pela ausência do efeito de diminuição na ingestão de sacarose pela submissão ao protocolo de estressores.

Há aqui, no entanto, um primeiro problema, que pode ser considerado um problema 
teórico. Quando avaliam a produção de efeitos do estresse no comportamento dos sujeitos, Silveira et al. (2004), Silveira et al. (2008) e Michaels e Holtzman (2006) consideram que o estresse produz aumento na ingestão de substâncias doces, enquanto Willner et al. (1987) dizem que o estresse diminui esse consumo. Com relação a esse problema, será aqui apenas salientada a relação descrita pelos primeiros: a manipulação neonatal produz maior consumo de substâncias doces. Essa relação será considerada independentemente de como é feita sua interpretação (se é por estresse ou não). Levando em conta, então, a possibilidade de que tal relação exista, ela pode ter sido responsável pela produção dos resultados no presente experimento, no que se refere à ingestão apresentada nos testes.

A segunda hipótese levantada é a de que a variável responsável pelas diferenças entre o presente estudo e os estudos relatados foi a exposição dos sujeitos à sacarose.

Em seu artigo, Willner et al. (1987) reportam o aumento na ingestão de sacarose e sacarina para seus grupos controle (não submetidos ao protocolo de estressores) ao longo do experimento. No entanto, os autores não discutem esse aumento, afirmando apenas que há uma tendência a esse aumento com o passar do tempo. Pode ser que a própria exposição à sacarose, portanto, aumente a ingestão apresentada pelos sujeitos. Não há, no entanto, argumento que explique tal fenômeno.

É dificil afirmar, ainda, aqui, que a exposição tenha aumentado a ingestão; se isso fosse verdade, deveria ocorrer para todos os sujeitos, já que todos foram expostos à sacarose pelo mesmo tempo. Uma possibilidade é a de que sujeitos que passaram pelo operante tenham ingerido maior quantidade de sacarose do que os que não passaram. Para os sujeitos que não passavam pelas sessões operantes, a quantidade média ingerida durante a sessão pelos sujeitos que eram submetidos a elas era disponibilizada. No entanto, nem todos os sujeitos consumiam toda a sacarose disponibilizada, e essa diferença pode ter produzido as diferenças encontradas. Dessa forma, pode ter havido diferença na quantidade ingerida entre os grupos, o que pode ter produzido a diferença nos resultados.

Conforme descrito no procedimento, os sujeitos passaram por 12 testes de ingestão e preferência por sacarose anteriormente ao período de exposição ao protocolo (completo ou incompleto), ou à segunda condição de privação. Além disso, os sete sujeitos que passaram por sessões operantes também tiveram essa condição presente durante as 12 semanas. Portanto, sua exposição à sacarose foi de duas vezes por semana, durante 12 semanas, anteriormente à condição de exposição à variável independente (protocolo completo ou incompleto ou privação).

Em estudo sobre a produção de analgesia pela exposição à sacarose, Segato, Castro-Souza, Segato, Morato e Coimbra (1997) relataram que os sujeitos expostos por 14 sessões à sacarose apresentaram maior resistência à dor do que sujeitos que não passaram por essa condição. Em seu estudo, essa resistência foi medida pela latência com que os sujeitos retiravam sua cauda de um compartimento que tinha a temperatura gradualmente aumentada. Para sujeitos expostos a apenas uma sessão de ingestão de sacarose, o mesmo não ocorreu (sua resistência à dor não foi alterada). Portanto, Segato et al. afirmaram que, quando expostos à sacarose por um grande período de tempo, os sujeitos passam a ter uma dife- 
rença na resposta a alguns estímulos (no caso, o estímulo doloroso "temperatura alta”).

No presente experimento, pelo fato de os sujeitos terem sido expostos continuamente durante um longo período à sacarose, os efeitos do protocolo podem ter sido "atenuados" por essa exposição. É como se esses estímulos, por conta da analgesia produzida pela sacarose, não produzissem o mesmo efeito que produziram em sujeitos que não tiveram tal história com a substância.

No estudo de Thomaz (2001, 2005), foram realizadas apenas cinco exposições à sacarose anteriormente ao protocolo (dois testes de adaptação e três testes de ingestão), para os sujeitos que não passaram pelas sessões operantes. Para os sujeitos que passaram por essas sessões, a exposição foi de 18 sessões. Em seu estudo, por haver tamanha diferença entre a exposição à sacarose para sujeitos que passaram e sujeitos que não passaram por sessões operantes, a mesma possibilidade para explicar a diferença entre os dois grupos de sujeitos poderia ser levantada. No entanto, nos estudos de Dolabela (2004) e Rodrigues (2005), além das duas sessões de adaptação à sacarose, foram realizados 12 e 16 testes, respectivamente, previamente ao protocolo. No caso desses estudos, a exposição prolongada à sacarose ocorreu, não tendo produzido os mesmos resultados do presente experimento. Portanto, essa hipótese não se confirma.

Ambas as hipóteses aqui apresentadas, no entanto, merecem investigação. $\mathrm{O}$ que o presente estudo propõe, de acordo com os resultados, é apenas a possibilidade de que exista tal relação.

É proposto, aqui, portanto, que o isolamento de cada uma dessas variáveis (manipulação neonatal e exposição à sacarose) seja feito, para que esclarecimentos sobre seu papel na produção ou não dos resultados esperados pela exposição ao protocolo sejam possíveis.

A avaliação da relação entre o protocolo de estressores (completo ou incompleto) e a privação na ingestão e preferência por sacarose deve considerar o papel da manipulação neonatal e da exposição à sacarose, para que seu esclarecimento possa ser feito. É salientado que estudos futuros que utilizem procedimentos similares não devem deixar de levar em consideração o possível papel dessas variáveis nos resultados obtidos.

\section{REFERÊNCIAS}

Barr, A. M., \& Phillips, A. (1998). Chronic mild stress has no effect on responding by rats for sucrose under a progressive ratio schedule. Psychology and Behavior, 64, 591-597.

Cardoso, L. R. D. (2008). Efeitos do esquema de intervalo variável na preferência e no consumo de líquidos apresentados por ratos submetidos ao chronic mild stress (Dissertação de mestrado). Pontificia Universidade Católica de São Paulo, São Paulo, SP, Brasil.

Dalla, C., Antoniou, K., Drossopoulou, G., Xagoraris, M., Kokras, N., Sfikakis, A., \& Papadopoulou-Daifoti, Z. (2005). Chronic mild stress impact: are females more vunerable? Neuroscience, 135, 703-714.

Dolabela, A. C. F. O. (2004). Um estudo sobre as possíveis interações entre o chronic mild stress e o desempenho operante (Dissertação de mestrado). Pontificia Universidade Católica de São Paulo, São Paulo, SP, Brasil.

Forbes, N. F., Stewart, C. A., Matthews, K., \& Reid, I. C. (1996). Chronic mild stress and sucrose consumption: validity as a model of depression. Physiology \& Behavior, 60, 1481-1484. 
Guimarães, M. A., \& Mázaro, R. (2004). Princípios éticos e práticos do uso de animais na experimentação. São Paulo: Universidade Federal de São Paulo.

Keehn, J. D. (1979). Psychopathology in animals: Research and clinical implications. Londres: Academic Press.

Konkle, A. T. M., Baker, S. L., Kentner, A. C., Barbagallo, L. S. M., Merali, Z., \& Bielajew, C. (2003). Evaluation of the effects of chronic mild stressors on hedonic and physiological responses: sex and strain compared. Brain Research, 992, 227-238.

Matthews, K., Forbes, N., \& Reid, C. (1995). Sucrose consumption as an hedonic measure following chronic unpredictable mild stress. Psychology \& Behavior, 57, 241-248.

Michaels, C. C., \& Holtzman, S. G. (2006). Neonatal stress and litter composition alter sucrose intake in both rat dam and offspring. Phisiology and Behavior, 89, 735-741.

Rodrigues, M. B. (2005). Interações entre o chronic mild stress e o desempenho operante: uma replicação de Dolabela (2004) (Dissertação de mestrado). Pontifícia Universidade Católica de São Paulo, São Paulo, SP, Brasil.

Segato, F. N., Castro-Souza, C., Segato, E. N., Morato, S., \& Coimbra, N. C. (1997). Sucrose ingestion causes opioid analgesia. Brazilian Journal of Medical and Biological Research, 30, 981-984.

Silveira, P. P., Portella, A. K., Clemente, Z., Bassani, E., Tabajara, A. S., Gamaro, G. D., Dantas, G., Torres, I. L. S., Lucion, A. B., \& Dalmaz, C. (2004). Neonatal handling alters feeding behavior of adult rats. Physiology \& Behavior, 80, 739-745.
Silveira, P. P., Portella, A. K., Crema, L., Correa, M., Nieto, F. B., Diehl, L., Lucion, A. B., \& Dalmaz, C. (2008). Both infantile stimulation and exposure to sweet food lead to an increased sweet food ingestion in adult life. Physiology \& Behavior, 93, 877-882.

Thomaz, C. R. C. (2001). O efeito da submissão ao chronic mild stress (CMS) sobre o valor reforçador do estímulo (Dissertação de mestrado). Pontifícia Universidade Católica de São Paulo, São Paulo, SP, Brasil.

Thomaz, C. R. C. (2005). O efeito da submissão a estressores crônicos e moderados. São Paulo: Educ. Vigorito, M., Kruse, C. B.; \& Carretta, J. (1994). Differential sensitivity of operant behaviors to changes in the concentration of a sucrose reinforcer: Effects of pimozide. Pharmacology Biochemistry and Behavior, 47, 515-522.

Willner, P. (1991). Behavioural models in psychopharmacology: Theoretical, industrial and clinical perspectives. Cambridge: Cambridge University Press.

Willner, P., Towell, A., Sampson, D., Sophokleous, S., \& Muscat, R. (1987). Reduction of sucrose preference by chronic unpredictable mild stress, and its restoration by a tricyclic antidepressant. Psychopharmacology, 93, 358-364.

Notas das autoras: Este artigo é dedicado à sua segunda autora, a professora doutora Tereza Maria de Azevedo Pires Sério (in memoriam).

Qualquer esclarecimento adicional sobre o estudo pode ser requisitado à primeira autora, via endereço eletrônico: < clarissa pereira@gmail.com>. 